\title{
CAN FORWARD RATES BE USED TO IMPROVE INTEREST RATE FORECASTS?
}

\author{
Emilio Domínguez ${ }^{1}$ \\ Alfonso N ovales ${ }^{2}$
}

A pril 1999

\begin{abstract}
1. Departamento de A nálisis E conómico. Universidad Pública de N avarra. Pamplona. Spain.

2. Departamento de Economía Cuantitativa. U niversidad Complutense. M adrid. Spain.
\end{abstract}

\begin{abstract}
We evaluate the extent to which the explanatory power detected in the term structure in different markets and countries can actually be used to produce sensible forecasts of future short-term interest rates. Specifically, in spite of the forecasting connotation of the unbiasedness property of forward rates, actual evaluation of their forecasting performance has received scant attention in the literature on the term structure. We use monthly data for 1978-1998 on interest rates on Eurodeposits on the US dollar, yen, Deutsche mark, British pound, Spanish peseta, French franc, Italian lira and Swiss franc, comparing forecasts obtained from forward rates to those obtained from univariate autoregressions. By themselves, forward rates produce better one-step ahead forecasts, as well as better once-and-for all forecasts of 1-month interest rates over a full year horizon than those obtained from the own past of interest rates. The gain in one-step ahead forecasting disappears for longer maturities, although forward rates still produce better once-and-for all predictions of 3-and 6-month interest rates than univariate autoregressions for a number of currencies.
\end{abstract}

Keywords: Expectations hypothesis, term structure, forward rates JEL Classification: E37, E43 


\section{INTRODUCTION}

The essence of the Expectations $\mathrm{H}$ ypothesis $(\mathrm{EH})$ of the term structure is that long-term rates are an average of current and expected future shorter-term interest rates. As an implication, there is a close link between short- and long-term rates, and their spread contains all relevant information on future changes in short-term rates. That is of utmost interest to market participants, who could otherwise hope to design profitable investment strategies using information currently available.

The ability of the EH to explain the behavior of interest rates over the term structure has been controversial for a long time [see Hamburger and Platt (1975), Fama and Bliss (1983), Shiller, Campbell and Schoenholtz (1983), Fama (1984), M ankiw and Summers (1984), M ankiw and M iron (1986), Fama and Bliss (1987), M ishkin (1988), Shiller (1990), Fama (1990), Campbell and Shiller (1987,1991), Jorion and M ishkin (1991), Jorion (1992) and Gerlach and Smets (1997), among many others]. M uch of this work consistently rejected the restrictions implied by the $\mathrm{EH}$, although providing evidence of explanatory power in the short/long-term interest rate spread on future short-term rates. By and large, changes predicted in future short-term rates by these models are small, suggesting a possible time varying risk or term premium. This may have also produced an impression that the forecasting ability of forward rates is not very high.

$\mathrm{M}$ ost tests of the $\mathrm{EH}$ have been implemented either as regressions of future short-term interest rates on current forward rates, or as regressions of future changes in short-term rates on the current spread between long- and short-term interest rates. Since these regressions explain future returns as functions of current information, they are usually referred to as capturing the fact that, if the EH holds, then the current term structure contains information useful to predict future interest rates. U sually, if the mentioned regressions produce significant coefficients and a high R-squared, the researcher will maintain the ability of the term structure to forecast future rates. This has been a standard practice since Fama (1976). That conclusion will have been reached on the basis of a good fit in the regressions, but not on their actual ability to forecast future interest rates. If, in addition, the slope of the forward rate in the projection of future interest rates has a unit slope, the forward rate is said to be an unbiased predictor of future interest rates.

However, in spite of the forecasting connotation of the unbiasedness property of forward rates, 
actual evaluation of the forecasting performance of forward rates has received scant attention in the literature on the term structure, may be due to skepticism on its possibilities [for an actual exercise on forecasting, see Deaves (1996). For forecasting conclusions based on goodness of fit, without actual forecasting, see Park and Switzer (1997), Wahab (1997), among many others].

In this paper we evaluate the extent to which the explanatory power detected in the term structure in the literature on different markets and countries can actually be used to produce sensible forecasts of future short-term interest rates. Interest rates on Eurodeposits, known as Eurorates, provide an interesting data set on which to test these issues. These deposits share important characteristics, not being distorted by differences in the fiscal treatment of returns or in the timing of interest payments, and not being affected by possible capital controls or other government regulations. That makes their returns more comparable than domestic rates. To the best of our knowledge, this is the first systematic attempt to measure the actual predictive power of the term structure under the restrictions of the Expectations Hypothesis on international data. A fter providing evidence on the relationships between interest rates and lagged forward rates, we analyze whether the estimated projections can in fact be used to produce improved short-term interest rate forecasts.

In Section 2 we review some concepts relating to the EH. In Section 3 we describe the goodness of fit of a variety of models capturing the restrictions of the EH, estimated with Eurocurrency interest rates. In Section 4 we describe the forecasting exercises and discuss their results. The paper closes with some conclusions.

\section{FOR WARD RATES AS PREDICTORS OF FUTURE SPOT RATES.}

A ccording to the $E H$, the return on an n-period investment, $r_{t}^{n}$, should be the average expected return on a roll-over strategy over that period, plus possibly a time invariant term or risk premium $\mathrm{B}^{\mathrm{n}, 1}$,

$$
r_{t}^{n} \cdot \frac{1}{n}{ }_{j^{\prime} 0}^{n \& 1} E_{t} r_{t \% \%}^{1} \% B^{n, 1}
$$

$E_{t} r_{t \%}^{1}$ being the current expectation, based on information available at time $t$, of the one-period interest rate prevailing in the market at time $t+\mathrm{j}$. W e work with annualized, continuously compounded rates of return, for which (1) is an exact expression. Under risk neutrality, the risk premium would 
be zero, although $\mathrm{B}^{n, 1}$ might still represent some constant term premium. The stronger version of the $\mathrm{EH}$ implies that there is no premium of any kind, long-term rates being just the average of current and expected future short-term rates, while the weaker version of the $\mathrm{EH}$ would allow for a significant constant in (1).

This expression can be generalized to consider rates of return on $\mathrm{n}$ - and $\mathrm{m}$-period investments, $n$ being a multiple of $m$,

$$
r_{t}^{n} \cdot \frac{m}{n} j_{j}^{\frac{n}{m} \& 1} E_{t} r_{t \% m m}^{m} \% B^{n, m}
$$

A $n$ interesting special case occurs when $n=2 m$, as in the comparison between returns on 3 and 6-month investments, or between returns on 6- and 12-month investments. Then,

$$
r_{t}^{n} \cdot \frac{1}{2}\left(r_{t}^{m} \% E_{t} r_{t \% m}^{m}\right) \% B^{n, m}
$$

so that in the case of a 3-month reference period, the rate of return on a 6 -month investment should be equal to the average of the rate of return on a 3-month investment and the rate of return on a 3month deposit expected to prevail 3 months hence, plus a possible term premium.

Under rational expectations, we have,

$$
r_{\mathrm{t} \% \mathrm{~m}}^{m}, E_{\mathrm{t}} \mathrm{r}_{\mathrm{t} \% \mathrm{~m}}^{\mathrm{m}} \% \mathrm{~g}_{\mathrm{t} \% \mathrm{~m}}^{m}
$$

where $g_{t \% m}^{m}$, the rational expectations error in forecasting $r_{t \% m}^{m}$ at time $t$, has a MA(m-1) structure. Finally, substituting (4) into (3) and subtracting $r_{t}^{m}$ from both sides, we get,

$$
r_{t}^{n} \& r_{t}^{m}, \frac{1}{2}\left(r_{t \% m}^{m} \& r_{t}^{m}\right) \& \frac{1}{2} g_{t \% m}^{m} \% B^{n, m}
$$

so that the current spread between long- and short-term interest rates (left hand side) should be a good predictor of future changes in the short-term rate (right hand side).

With continuously compounded rates of return, implicit forward rates are defined by $(n \& m) f_{t, t \% m}^{n \& m}{ }^{n} n r_{t}^{n} \& m r_{t}^{m}$. Hence, with $n=2 m$, we have: $f_{t, t \% m}^{m}{ }^{\prime} 2 r_{t}^{2 m} \& r_{t}^{m}$ so that using (3) and (4), 


$$
r_{t \% m}^{m}, f_{t, t \% m}^{m} \& 2 B^{2 m, m} \% g_{t \% m}^{m}
$$

The rational expectations version of the $\mathrm{EH}$ of the term structure of interest rates has often been discussed by analyzing whether its implication (6) holds in a particular market. To that end,

$$
r_{t \% m}^{m}, \quad \% \$ f_{t, t \% m}^{m} \% u_{t} \% m
$$

is usually estimated, testing the hypothesis $\mathrm{H}_{0}:$ : $=0, \$=1$, which is referred to as the forward rate being an unbiased predictor of the future spot rate. Under the stronger version of the $\mathrm{EH}$ (incorporating neutrality) there is no risk or term premia, so $\mathrm{H}_{0}$ should hold. In that case (4) and (6) imply that forward rates, which are known at time $t$, are just expectations of future short term rates:

$\mathrm{f}_{\mathrm{t}, \mathrm{t} \% \mathrm{~m}}^{\mathrm{m}}{ }^{\prime} \mathrm{E}_{\mathrm{t}} \mathrm{r}_{\mathrm{t} \% \mathrm{~m}}^{\mathrm{m}}$. A weaker version of the $\mathrm{EH}$ allows for a constant risk/term premium and suggests

testing: $H_{0}{ }^{\prime}:$ \$ 1 in (7). When significant, " will be a negative multiple of the possible risk/term premium $B^{2 m, m}$. This analysis is specially interesting in the comparisons of 3-versus 6 -month rates, and 6- versus 12-month rates, since the 3- and 6-month are some of the more actively traded maturities in most financial markets. The one-month interest rate is also of great interest, but it needs an assumption of the form: $E_{t} r_{t \%}^{1}{ }^{1} E_{t} r_{t \% 2}^{1}$ to relate expectations one and two periods ahead, since this comparison does not exactly fit our framework. W ith that, and the definition of the 2-month forward rate: $2 \mathrm{f}_{\mathrm{t}, \mathrm{t} \%}^{2} 3 \mathrm{r}_{\mathrm{t}}^{3} \& \mathrm{r}_{\mathrm{t}}^{1}$, a regression similar to (7) can be run to test unbiasedness of the 2-month forward rate, relative to the future one-month spot rate. In this case, the intercept will be equal to $(3 / 2) B^{3,1}$.

\section{LONG-RUN RELATIONSHIPS BETWEEN CURRENT FORWARD AND FUTURE INTEREST RATES}

Hence, as shown in (7), if the EH holds true, implicit forward rates should summarize all 
information contained in the term structure, relevant to forecast future spot rates, and the slope in a projection like (7) should be equal to one. Besides, under the stronger version of the hypothesis, the intercept " should be zero.

As with many other term structure characteristics, empirical evidence on this area is somewhat contradictory. Even though initial work with US Treasury bill data [Shiller, Campbell and Schoenholtz (1983), Fama (1984), Fama and Bliss (1987) and Shiller (1990)] consistently rejected the restrictions implied by the $\mathrm{EH}$, it provided evidence on the existence of explanatory power in the short/long-term interest rate spread on future short-term rates. Fama (1990) and M ishkin (1988) both found that the spread contained information on short-term rates several periods into the future. Fama and Bliss (1983) concluded that, over 1964-1985, one year forward rates on Treasury bills contained information on expected returns on bills one year in advance. M ankiw and Summers (1984) and M ankiw and M iron (1986) analyzed 3- and 6-month U S rates, concluding that the term structure had important explanatory power for future interest rates, although it seems to have faltered after the founding of the Federal Reserve System. Campbell and Shiller $(1987,1991)$ found again that the restrictions of the EH do not hold, but that the US spread explains the direction of changes in short-term rates. However, the predicted changes are small, suggesting a possible time varying risk or term premium. Similar results were obtained by Jorion and M ishkin (1991). W orking with 1973-1988 data, Jorion (1992) also found that in the market for US dollar and Deutsche mark eurodeposits the forward/spot spread contains information on future spot rate changes. On the other hand, Hamburger and Platt (1975) and Shiller, Campbell and Schoenholtz (1983) working with data on different markets, both concluded that the predictive power of forward rates, in the sense of providing a good explanatory power of future interest rates, is scarce.

In recent work with Eurorates, Gerlach and Smelts (1997) have estimated regressions of cumulative changes in short-term rates on current spreads, finding general evidence in favor of a unit slope, in consistency with the $\mathrm{EH}$, although results differ widely over countries. Those regressions include, in special cases, model (7). These authors have estimated the relationships of 3-, 6- and 12month to the 1-month Euro-rates, for 17 countries, finding strong support for the hypothesis that the term spread does predict future short rate movements. Domínguez and Novales (1999) implement a battery of tests of $\mathrm{EH}$ on Eurorates on a variety of currencies and a wider array of maturity comparisons, finding general support for the hypothesis in a long sample, 1978-1997.

We use in this paper monthly averaged bid rates on 1-, 3-, 6-, and 12-month deposits from the L ondon eurocurrency market for the US dollar, J apanese yen, German mark, British pound, Spanish peseta, French franc, Italian lira and Swiss franc, between J anuary 1979 and December 1998, in their 
annualized, continuous equivalent form. Data for Spain started on June 1980. As an illustration, Figures 1 and 2 show the 1-month interest rates and 3-month forward rates (obtained from 3- and 6month interest rates) to be apparently nonstationary. In fact, A ugmented Dickey Fuller (ADF) and Phillips-Perron tests for the presence of a unit root in forward rates $f_{t, t \%}^{2}, f_{t, t \%}^{3}$ and $f_{t, t \%}^{6}$ in the eight currencies we consider (not shown to save space) provided evidence in favor of that hypothesis, at the same time the null hypothesis of two unit roots was rejected in favor of the alternative of a single root.

Consequently, (7) must be interpreted as a possible cointegrating relationship between current forward and future spot rates, on which to test the restrictions implied by the $\mathrm{EH}$. Cointegration between interest rates over the term structure of a currency is consistent with the idea that market forces continuously adjust to correct any temporary disequilibrium, so that risk adjusted rates of return on different maturities do not drift apart permanently, which would otherwise give rise to arbitrage opportunities.

Column 2 in Table 1 contains the Maximum eigenvalue and Trace statistics to test for the number of cointegrating relationships between spot and lagged forward rates, which seems to be one in all cases, except at the 3-month horizon for the US dollar, D eutsche mark, Spanish peseta and Swiss franc, and the 6-month returns on deposits in D eutsche marks. There is some ambiguity for the 1month interest rate for the peseta and the 6-month rates on the Swiss franc. There cannot be two cointegrating vectors, since both variables are I(1). M aximum likelihood estimates [] ohansen (1988, 1991)] of the single cointegrating vector are shown in the middle panel, even in the cases where the test failed, together with the number of lags used in the VAR specification. Slope estimates are again very close to one, being above that level in about half of the cases.

L ooking at the estimated maximum-likelihood standard deviations, we would reject the null hypothesis that the slope is equal to one for the 3- and 6-month interest rate models for the yen, B ritish pound and Italian lira, the 1-month interest rate on the Deutsche mark and the 6-month rate on the Swiss franc. A more formal, likelihood ratio test of the unit slope hypothesis [J ohansen $(1988,1991)]$ (column 4 in Table 1) leads to rejection again for the 3- and 6-month interest rate models for the yen, the 3-month rate on the British pound, and the 6-month rate on the Swiss franc, 4 of the 24 cases at the $1 \%$ significance level and in 6 cases at the $5 \%$ level, since we have to add the 6 -month rate regression for the Deutsche mark and British pound. F our of the six rejections of this implication of the $E H$ arise in the 6-month horizon, suggesting that the lower liquidity at the 12-month maturity may explain most of these observed deviations from the $\mathrm{EH}$.

Rejection of the unit slope hypothesis at the $5 \%$ significance level comes together with a 
significant negative constant in most cases, since it always arises for slope estimates above one. Even when the hypothesis is not rejected, negative estimates for the intercept are obtained in all but five cases, which would be consistent with the existence of term/risk premia. B esides, the supposed premia seem to increase with maturity in most countries, as it should be expected. However, in most cases our intercept estimates are not significant, although specially for the peseta and F rench franc, lack of significance arises from estimates not being very precise. By and large, we cannot claim to have found consistent evidence of constant risk premia.

If we impose the restrictions of the $\mathrm{EH}$ in the form of a unit slope on forward rates and test for stationarity of the differences $\quad r_{t}^{m} \& f_{t \& m, t}^{m}, m^{\prime} 1,3,6 \quad$ [last column in Table 1], we reject the unit root hypothesis at the 95\% confidence level for all currencies and maturities, although the evidence on the 6-month Swiss franc rate is not totally clear. With this qualification, these tests suggest that (1,1) may be considered to be the approximate cointegrating vector between each of the 1-, 3- and 6month returns and the corresponding forward rate, appropriately lagged, in support of the EH. It might well be that imposing the restrictions on the cointegrating vector increases the power of the test, allowing for more evidence of cointegration to emerge. However, preference for the likelihood-ratio test or the ADF/PP tests should rely on their finite sample properties, for which not much is known.

To summarize the results in this Section: a) there is overwhelming evidence in favor of forward rates having explanatory power for future short term spot rates, b) unbiasedness of the forward rate is an acceptable hypothesis, having found just some ambiguous evidence for some of the 6- versus 12-month comparisons, and c) we have not found consistent evidence of constant risk premia.

We discuss in the next Section whether this evidence can, in fact, be used to improve upon univariate interest rate forecasting.

\section{CAN THE TERM STRUCTURE BE USED TO FORECAST INTEREST RATES?}

The results in the previous sections show that the term structure of Eurocurrencies contains significant information regarding future interest rate fluctuations, suggesting that it might be possible to exploit that information when forecasting interest rates. However, a good fit does not always come together with a good forecasting performance, and it is particularly interesting to check how the explanatory power we have documented in the forward rate translates into good forecasting 
performance. Evaluating the performance of the forward rate model (7) and comparing it with interest rate forecasts obtained from univariate autoregressive models in our international data set is the goal of this Section.

To check whether forward rates can be used to predict future interest rates, we estimated (7) for 1-, 3- and 6-month, with data through December 1997 and obtained forecasts over 1998, computing forecast accuracy measures for the whole year. To make sure that our results were not spurious, we also estimated with data up to December 1996, forecasting over 1997. No lagged interest rate was ever included in (7), which had the appropriately lagged forward rate as its only explanatory variable. For each two maturities, the predictive power of the forecasting model was compared with that of an autoregression in first differences of the short-term rate.

For most interest rates considered in our sample, the restrictions imposed by a random walk model would not be rejected at standard significance levels but, trying to improve forecasts, we forced some structure and fit an $A R(2)$ model to their first differences, from which we obtained monthly univariate forecasts over 1998. In fact, the AR(2) model turns out to predict significantly better than a random walk model in most cases. We computed static and dynamic forecasts. Static forecasts are one-month ahead predictions, in which actual data was used for the lagged explanatory variable, as needed. Dynamic forecasts are once and-for-all predictions over all 1998, obtained with data up to December 1997. They are progressively based on previous forecasts, as we run out of actual data. To obtain dynamic forecasts from (7) for the three-month interest rate, we used actual data on forward rates up to the A pril 1998 forecast. Starting in A pril, predictions of forward rates must be obtained in advance, to be used as the explanatory variable in the forecasting exercise. To that end, an AR(2) model was again fitted to the first difference of the forward rate in all cases. Similar strategies apply to the computation of static and dynamic forecasts of the one- and six-month rates in each currency. It must be emphasized that the forward rate is the only explanatory power in this forecasting model.

Table 2 contains the R oot M ean Square Error (RMSE), M ean A bsolute Error (MAE), and Theil's inequality coefficient $U$ as performance measures in the static and dynamic forecasting exercises:

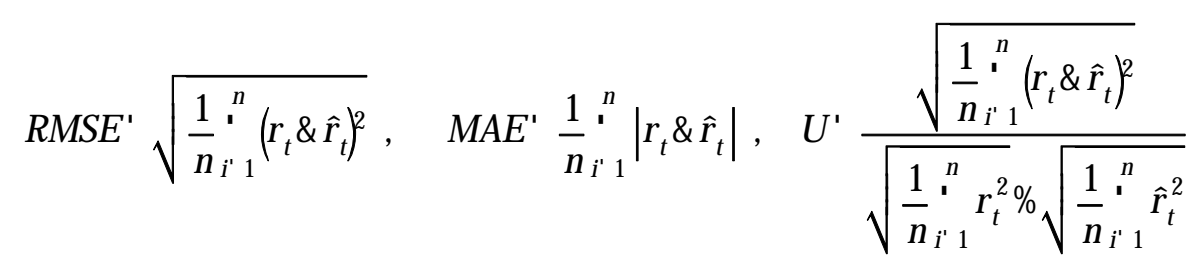

Theil's $U$ falls between 0 (in case of a perfect fit) and 1 (very bad forecasting performance). 
Percent R oot M ean Square Errors are not advisable in this exercise, since interest rates are often small in absolute value over the forecasting horizon, to the point that even acceptable forecast errors might produce huge percent errors for a single period, dominating the value of any time aggregate forecasting performance indicator. Hence, we use their versions in absolute terms. There are two rows of forecast indicators for the Forward model. The upper row is obtained under least-squares estimation of the projection of interest rates on lagged forward rates, while the lower row is obtained under the maximum-likelihood estimates [Johansen (1988, 1991)], i.e., using the estimated cointegrating relationship between interest rates and lagged forward rates. As we will see, there are some differences in forecasting performance between both methods, generally in favor of the least squares projection.

In one-step-ahead (static) forecasts of 1-month interest rates, the forward rate model produces better forecasts than those obtained from the own past of interest rates [left panel in Table 2] for the U S dollar, yen, British pound, Spanish peseta and Swiss franc for 1998, and for the US dollar, yen, Deutsche mark, British pound, Spanish peseta and F rench franc for 1997. A similar average reduction is achieved in the RMSE, MAE and U statistics by the forward model, relative to univariate models, being of $27 \%$ and $13 \%$, respectively, for 1997 and 1998. The estimated cointegrating relationship would have produced better 1998 static forecasts for the Italian lira, but the gain does not seem to be significant.

Results are even more evident when forecasting over a longer horizon [right panel in Table 2]. At the end of 1997, the forward rate model would have predicted 1-month interest rates over a full year horizon better than the univariate model in all currencies except the Swiss franc. There is a broad gain in dynamic forecasting performance from using the forward model. For 1997 forecasts, forward models would have beaten univariate models for the yen, British pound, Spanish peseta, French franc, I talian lira and Swiss franc. However, the average reduction in each of the RMSE, MAE and U statistics is now 28\% for 1997, and 21\% for 1998.

The improvement produced by the forward model in static forecasting performance disappears for longer maturities [left panels in Tables 3 and 4]. There is not even one currency for which the forward model beats the univariate model in static predictions of 3- and 6-month interest rates. It is clear that the gain from using forward rates is concentrated in dynamic forecasting, suggesting that forward rates anticipate possible changes in trend better than the own past of the interest rate being predicted. This is very much in consistency with the spirit of the EH. Searching for the causes of this regularity looks as an interesting issue for further research, for which decomposing spot and forward rates into transitory (short-term) and permanent (long-term) components might be an interesting 
approach.

On the other hand, the forward model still produces better dynamic forecasts than univariate models for a number of currencies every year. The forward rate model beats the univariate autoregression in once-and-for all forecasting of 3-month interest rates over all 1998 for the U S dollar, F rench franc and Italian lira, and for the U S dollar, yen, D eutsche mark, British pound, Spanish peseta and French franc over 1997 [right panel in Table 3]. The average reduction in performance statistics is now of $28 \%$ both, for 1997 and 1998. For 6 -month rates, the forward model produces better onceand-for-all forecasts than the univariate model for the British pound, French franc and Italian lira for 1998, and for the US dollar, Deutsche mark, British pound and French franc over 1997 [right panel in Table 4]. The maximum likelihood cointegrating relationship would have produced better 6-month interest rate forecasts than both, the univariate model and the least-squares forward model for the US dollar and Spanish peseta over 1998, and the Swiss franc over 1997. Forecasting gains at these horizons are again important: a reduction of $28 \%$ is uniformly achieved in the RMSE, MAE and U statistics. A verage reductions are now of $19 \%$ for 1997 , and $34 \%$ for 1998 .

As a final exercise, we computed interest rate predictions under the unbiasedness property of forward rates, i.e., we used the appropriate forward rate itself as a predictor of future interest rates. The results were not too bad for the shorter maturity: in 9 of the 16 static and dynamic forecast comparisons for 1-month interest rates for 1998, these restricted projection produced better forecasts than the estimated cointegrating relationship between interest rates and forward rates. In 4 of those 9 cases, they were, in fact, the best predictions. But, once again, the performance of the restricted projection deteriorated over longer maturities: in just 7 of the 16 forecast comparisons for 3-month interest rates, and in only 2 comparisons for 6 -month rates, the restricted projection produced better forecast than the estimated projection, but they were never the best, being beaten by either those obtained from the least-squares projection or from the univariate model. Although there might be some gain to be exploited from fully imposing the restrictions of the $\mathrm{EH}$ when predicting 1-month rates, versus using the estimated interest rate/forward rate relationship, it seems hard to know a priori when that will be the case. In particular, we have not detected any connection with the results of testing for a unit slope in Table 1.

Focusing on dynamic forecasts, the forecasts obtained from the least-squares projection of interest rates on forward rates were better than those from univariate models in 29 out of the 48 forecasting exercises run for 1997 and 1998. Forecasts from the maximum-likelihood estimates of that projection as a cointegrating relationship were better than those from univariate models in 20 of the 48 comparisons, 16 of which in company of predictions obtained from the least-squares projection. 
That the forecasting ability of forward rates is much better for shorter maturities should be expected. We have seen in Table 1 that the restrictions of the $\mathrm{EH}$ sometimes fail to hold for the longer maturities, so it is not surprising that a model that incorporates such restrictions might not forecast too well. N evertheless, the fact that forward rates can predict quite well 1-month interest rates one month in advance is quite remarkable, since it is in this case the 3-month/1-month spread which is being used, by itself, to forecast future 1-month rates one month in advance, without using lags of the interest rate being forecasted. That this spread can forecast even better than the own past of the 1-month interest rate should be seen as strong evidence in favor of the $\mathrm{EH}$ for short maturities from a practical point of view which is of fundamental relevance to the market participant, but not often documented.

\section{CONCLUSIONS}

The Expectations $\mathrm{H}$ ypothesis on the formation of the term structure of interest rates leads to regressions that purport to explain future short-term rates as functions of current forward rates. U sually, a good fit of these regressions has been interpreted as the forward rate having significant predictive power for future short-term interest rates, which is considered to be the essence of the Expectations $\mathrm{H}$ ypothesis. In fact, a zero intercept together with a unit slope in that projection of future interest rates on current forward rates is known as the forward rate being an unbiased predictor of future interest rates. However, a true forecasting exercise has rarely been conducted.

We have examined the actual predictive power of those projections using 1-, 3- and 6-month interest rate monthly data for 1978-1998 on Eurodeposits on the US dollar, yen, Deutsche mark, British pound, Spanish peseta, French franc, I talian lira and Swiss franc, comparing such forecasts to those obtained from univariate autoregressions. Quite strikingly, our analysis shows that, by themselves, forward rates produce better one-step ahead forecasts, as well as better once-and-for all forecasts of 1-month interest rates over a full year horizon than those obtained form the own past of interest rates. That the information contained in forward rates can be put to that end is quite remarkable evidence in favor of the Expectations Hypothesis, at least over the shorter end of the maturity spectrum. However, the gain in one-step ahead forecasting disappears for longer maturities. Forward rates still produce better once-and-for all predictions of 3- and 6-month interest rates than univariate autoregressions for 
a number of currencies.

A strict interpretation of the EH would lead to using the appropriately lagged forward rate itself as a predictor of future interest rates. A gain just for 1-month rates, such forecasts are in some cases still better than those obtained from the estimated projection of future interest rates on forward rates, although we have not found a way to detect a priori when such improvement will arise. Some more work is needed along this line. 


\section{REFERENCES}

Campbell, J.Y. and Shiller, R.J., 1987, Cointegration and test of present value models", J ournal of Political Economy 95, 1062-1088.

Campbell, J.Y . and Shiller, R.J., 1991, Y ield spreads and interest rates movements: A bird's eye view, Review of Economic Studies, 58, 495-514.

Deaves, R., 1996, Forecasting Canadian short-term interest rates, Canadian Journal of Economics, $29,615-634$.

Fama, E., 1976, Forward rates as predictors of future spot rates, J ournal of Financial Economics, $13,509-528$

Fama, E., 1984, The information in the term structure, J ournal of Financial Economics, 13, 509-528.

Fama, E., 1990, Term structure forecasts of interest rates, inflation and real returns, J ournal of M onetary Economics, 25, 59-76.

Fama, E., and Bliss, R., 1987, The information in long maturity forward rates, American Economic Review, 77, 680-692.

Jorion, P. and M ishkin, F., 1991, A multicountry comparison of term-structure forecasts at long horizons, J ournal of Financial Economics, 29, 59-80.

M ankiw, N. and M iron, J.A., 1986, The changing behavior of the term structure of interest rates, The Q uarterly J ournal of Economics, 101, 211-228.

M ankiw, N. and Summers, L.H., 1984, Do long term rates overreact to short-term interest rates?, Brookings Papers on Economic Activity, 1, 223-242.

M ishkin, F, 1988, The information in the term structure: Some further results, J ournal of Applied Econometrics, 3, 307-314.

Park, T.H. and Switzer, L.N., 1997, Forecasting interest rates and yield spreads: the information content of implied futures yields and best-fitting forward rate models, J ournal of F orecasting, $16,209-224$.

Shiller, R.J., 1990, The term structure of interest rates, in B. Friedman and F. Hahn (eds.), Handbook of M onetary Economics, N orth-Holland, A msterdam.

Shiller, R.J., Campbell, J.Y., and Schoenholtz, K.L., 1983, Forward rates and future policy: interpreting the term structure of interest rates, Brookings Papers on Economic Activity, 1, 173-217.

Wahab, M ., 1997, On risk, rationality and the predictive ability of European short-term adjusted yield 
spreads, J ournal of International Money and Finance, 25, 29-46. 


\begin{tabular}{|c|c|c|c|c|c|c|c|}
\hline \multicolumn{7}{|c|}{$\begin{array}{l}\text { Table } 1 \\
\text { Estimated cointegrating relationship: } \\
r_{t}^{m}, " \% f_{t \& m, t}^{m} \% u_{t}, \quad m^{\prime} 1,3,6\end{array}$} & \\
\hline & & $8_{\max } / \operatorname{Trace}^{\mathrm{a}}$ & $\begin{array}{l}\text { Parameter e } \\
\qquad \mathrm{b}\end{array}$ & $\begin{array}{c}\text { nates: } 1984-1998 \\
\$^{b}\end{array}$ & $n^{c}$ & $\mathrm{H}_{0}: \$=1^{\mathrm{d}}$ & $\begin{array}{c}\text { ADF and Phillips- } \\
\text { Perron statistics } \\
\qquad r_{t}^{m}-f_{t-m, t}^{m}\end{array}$ \\
\hline US & $\begin{array}{l}1 \mathrm{~m} . \\
3 \mathrm{~m} . \\
6 \mathrm{~m}\end{array}$ & $\begin{array}{c}15.0^{*} / 22.1^{* *} \\
10.9 / 14.1 \\
14.8^{*} / 19.0^{*}\end{array}$ & $\begin{array}{l}-0.024(0.251) \\
-0.138(0.183) \\
-0.415(0.296)\end{array}$ & $\begin{array}{l}0.979(0.010) \\
0.983(0.019) \\
0.986(0.037)\end{array}$ & $\begin{array}{r}4 \\
12 \\
12\end{array}$ & $\begin{array}{l}1.28(0.26) \\
0.04(0.84) \\
0.36(0.55)\end{array}$ & $\begin{array}{l}-5.6(2) /-10.0 \\
-4.8(9) /-5.7 \\
-3.7(12) /-4.3\end{array}$ \\
\hline Yen & $\begin{array}{l}1 \mathrm{~m} . \\
3 \mathrm{~m} . \\
6 \mathrm{~m}\end{array}$ & $\begin{array}{l}29.6^{* * *} / 31.8^{* * *} \\
23.8^{* * *} / 26.5^{* * *} \\
17.5^{* * *} / 19.4^{*}\end{array}$ & $\begin{array}{l}-0.067(0.039) \\
-0.137(0.042) \\
-0.278(0.135)\end{array}$ & $\begin{array}{l}0.998(0.008) \\
1.029(0.008) \\
1.081(0.027)\end{array}$ & $\begin{array}{c}9 \\
6 \\
12\end{array}$ & $\begin{array}{c}0.29(0.59) \\
13.56(0.00) \\
12.58(0.00)\end{array}$ & $\begin{array}{l}-7.2(3) /-13.0 \\
-5.9(3) /-6.9 \\
-4.8(2) /-4.1\end{array}$ \\
\hline DM & $\begin{array}{l}1 \mathrm{~m} . \\
3 \mathrm{~m} . \\
6 \mathrm{~m}\end{array}$ & $\begin{array}{c}121.9^{* * *} / 25.0^{* *} \\
12.8 / 16.4 \\
11.0 / 13.8\end{array}$ & $\begin{array}{r}0.324(0.182) \\
-0.151(0.182) \\
-0.568(0.286)\end{array}$ & $\begin{array}{l}0.918(0.030) \\
0.996(0.028) \\
1.071(0.044)\end{array}$ & $\begin{array}{c}12 \\
4 \\
12\end{array}$ & $\begin{array}{l}0.02(0.90) \\
2.20(0.14) \\
4.46(0.03)\end{array}$ & $\begin{array}{l}-3.8(12) /-9.9 \\
-3.8(6) /-5.6 \\
-4.2(12) /-4.0\end{array}$ \\
\hline BP & $\begin{array}{l}1 \mathrm{~m} . \\
3 \mathrm{~m} . \\
6 \mathrm{~m}\end{array}$ & $\begin{array}{c}18.7^{* *} / 20.8^{* *} \\
22.1^{* * *} / 25.6^{* * *} \\
16.2^{* *} / 18.6^{*}\end{array}$ & $\begin{array}{l}-0.335(0.176) \\
-0.606(0.293) \\
-1.500(0.434)\end{array}$ & $\begin{array}{l}1.025(0.017) \\
1.064(0.029) \\
1.138(0.043)\end{array}$ & $\begin{array}{l}4 \\
6 \\
7\end{array}$ & $\begin{array}{l}4.38(0.04) \\
8.45(0.00) \\
7.55(0.01)\end{array}$ & $\begin{array}{l}-8.8(1) /-9.4 \\
-4.2(6) /-5.5 \\
-5.0(1) /-4.1\end{array}$ \\
\hline$S P$ & $\begin{array}{l}1 \mathrm{~m} . \\
3 \mathrm{~m} . \\
6 \mathrm{~m}\end{array}$ & $\begin{array}{c}14.1^{*} / 17.7 \\
11.5 / 13.9 \\
17.9^{* *} / 21.1^{* *}\end{array}$ & $\begin{array}{r}0.375(0.454) \\
0.381(0.505) \\
-0.702(0.476)\end{array}$ & $\begin{array}{l}0.954(0.038) \\
0.973(0.042) \\
1.043(0.039)\end{array}$ & $\begin{array}{c}6 \\
6 \\
10\end{array}$ & $\begin{array}{l}0.13(0.72) \\
0.48(0.49) \\
1.29(0.26)\end{array}$ & $\begin{array}{l}-4.8(4) /-10.2 \\
-4.4(4) /-6.1 \\
-5.9(4) /-4.0\end{array}$ \\
\hline $\mathrm{FF}$ & $\begin{array}{l}1 \mathrm{~m} . \\
3 \mathrm{~m} . \\
6 \mathrm{~m} .\end{array}$ & $\begin{array}{c}19.4^{* *} / 23.1^{* *} \\
16.2^{* *} / 19.6^{*} \\
22.1^{* * *} / 26.2^{* * *}\end{array}$ & $\begin{array}{l}-0.259(0.404) \\
-1.103(1.018) \\
-0.750(1.145)\end{array}$ & $\begin{array}{l}1.011(0.049) \\
1.146(0.133) \\
1.081(0.141)\end{array}$ & $\begin{array}{r}9 \\
12 \\
12\end{array}$ & $\begin{array}{c}0.10(0.75) \\
1.20(0.27) \\
1.44(0.23)\end{array}$ & $\begin{array}{l}-3.7(6) /-12.1 \\
-9.4(9) /-5.3 \\
-4.2(7) /-5.7\end{array}$ \\
\hline LI & $\begin{array}{l}1 \mathrm{~m} . \\
3 \mathrm{~m} . \\
6 \mathrm{~m} .\end{array}$ & $\begin{array}{c}17.0^{* *} / 22.0^{*} \\
17.2^{* *} / 21.0^{*} \\
25.3^{* * *} / 29.9^{* * *}\end{array}$ & $\begin{array}{l}0.417(0.348) \\
0.938(0.440) \\
0.876(0.314)\end{array}$ & $\begin{array}{l}0.951(0.030) \\
0.882(0.037) \\
0.882(0.025)\end{array}$ & $\begin{array}{l}12 \\
12\end{array}$ & $\begin{array}{l}2.02(0.16) \\
1.22(0.27) \\
2.84(0.09)\end{array}$ & $\begin{array}{l}-4.3(10, c) / 12.0 \\
-3.1(12) /-5.8 \\
-4.2(7, c) /-4.0\end{array}$ \\
\hline SF & $\begin{array}{l}13 \mathrm{~m} . \\
3 \mathrm{~m} . \\
6 \mathrm{~m} .\end{array}$ & $\begin{array}{c}19.1^{* *} / 20.5^{* *} \\
13.2 / 15.3 \\
14.0^{*} / 15.6\end{array}$ & $\begin{array}{l}-0.230(0.137) \\
-0.235(0.121) \\
-0.455(0.189)\end{array}$ & $\begin{array}{l}1.013(0.026) \\
1.019(0.022) \\
1.105(0.037)\end{array}$ & $\begin{array}{l}12 \\
6 \\
7\end{array}$ & $\begin{array}{l}1.41(0.24) \\
1.06(0.30) \\
8.29(0.00)\end{array}$ & $\begin{array}{l}-6.3(3, c) /-8.8 \\
-4.7(7, c) /-4.2 \\
-2.4(12) /-3.2\end{array}$ \\
\hline
\end{tabular}

Notes: (a) Maximum eigenvalue and Trace statistics. Their critical values when testing the existence of zero cointegrating relationship, at the $10 \%, 5 \%$ and $1 \%$ significance levels, are $13.8,15.7$ and 20.2 for the Maximum eigenvalue, and 17.8, 20.0 and 24.7, for the Trace statistic (Osterwald-L enum (1992)).

(b) N umbers in brackets are maximum-likelihood standard errors.

(c) Number of lags used in the VAR in first differences.

(d) Likelihood ratio statistic to test the null hypothesis that the cointegrating vector is $(1,-1)$.

(e) $\quad A D F$ and Phillips-Perron statistics for presence of a unit root in the difference between future rates and current forward rates. Number of lags used in ADF test are shown in brackets. Critical values for both tests at the 10\%, $5 \%$ and $1 \%$ significance levels are $-1.62,-1.94$ and -2.57 when no constant is included in the vector autoregression, and $-2.57,-2.87$ and -3.46 when a constant is included. 
Table 2

1-month interest rates

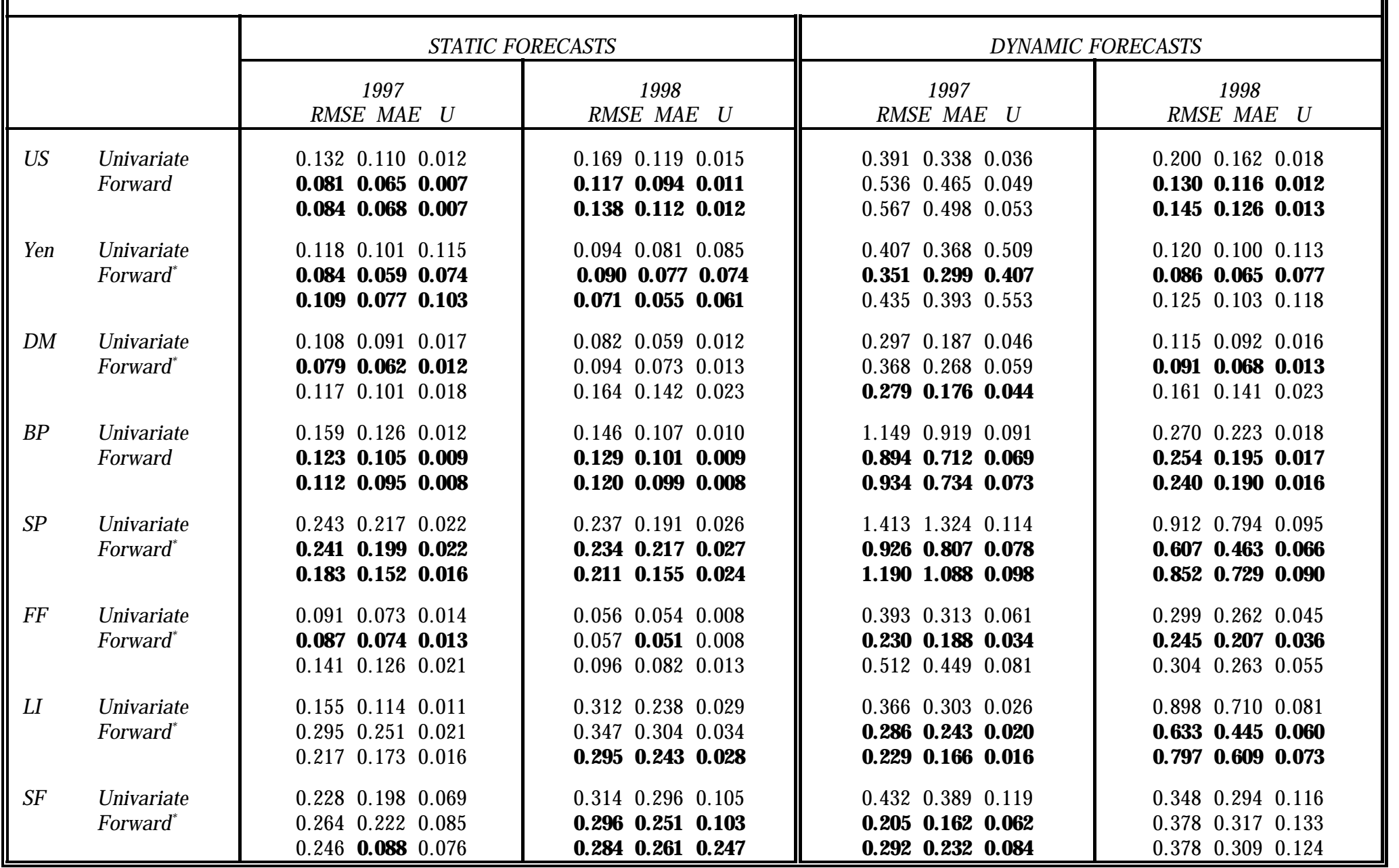

Note: $\quad$ Root M ean Square Error (RM SE), M ean A bsolute Error (M AE) and Theil's U statistics for static and dynamic forecasts obtained from AR(3) univariate autoregressions, as well as from a regression of the interest rate on the corresponding forward rate, appropriately lagged.

Bold figures denote cases where the Forward model predicts better than the univariate model. 
Table 3

3-month interest rates

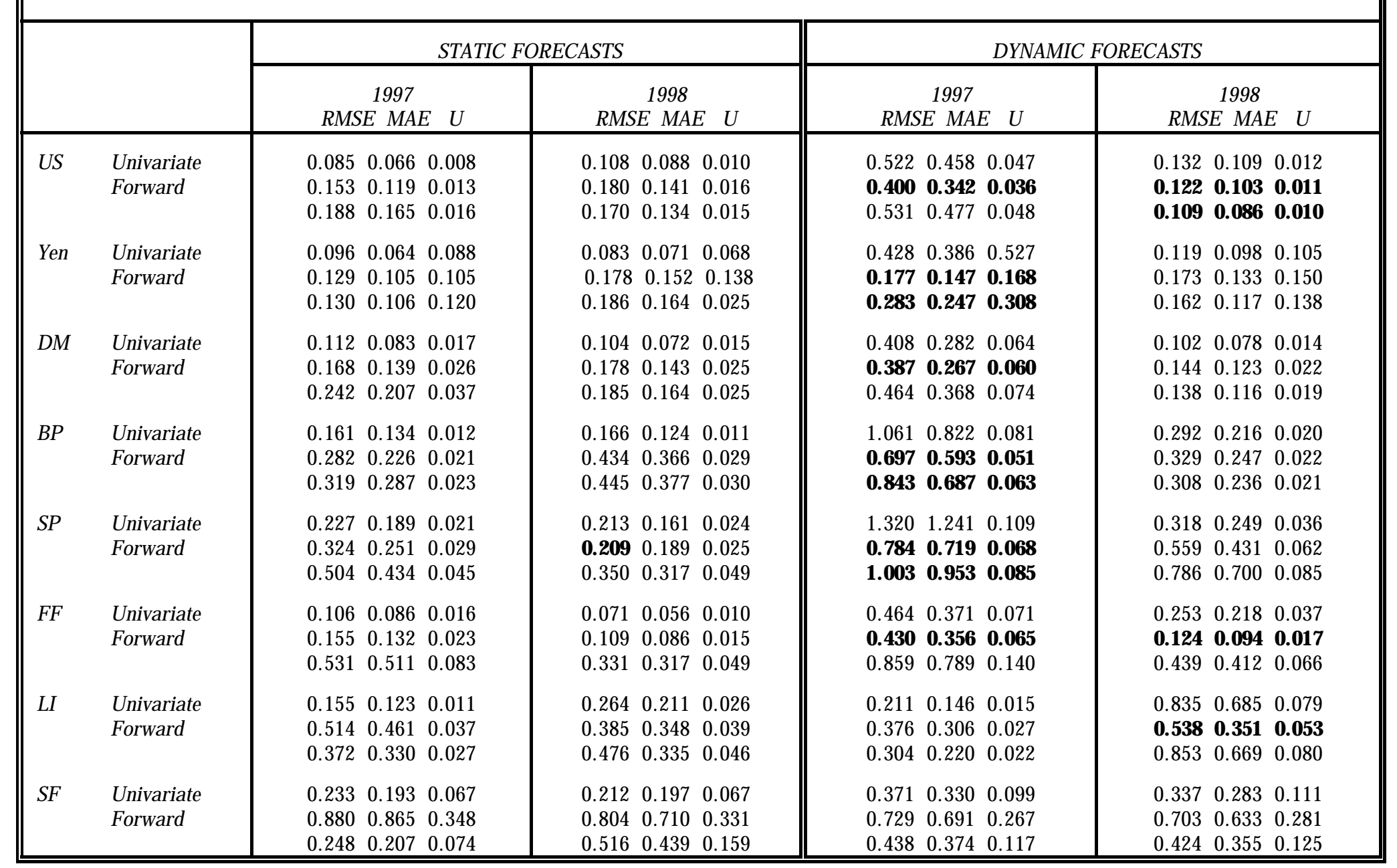

Note: $\quad$ Root M ean Square Error (RM SE), M ean A bsolute Error (M AE) and Theil's U statistics for static and dynamic forecasts obtained from AR (3) univariate autoregressions, as well as from a regression of the interest rate on the corresponding forward rate, appropriately lagged.

Bold figures denote cases where the Forward model predicts better than the univariate model. 
Table 4

6-month interest rates

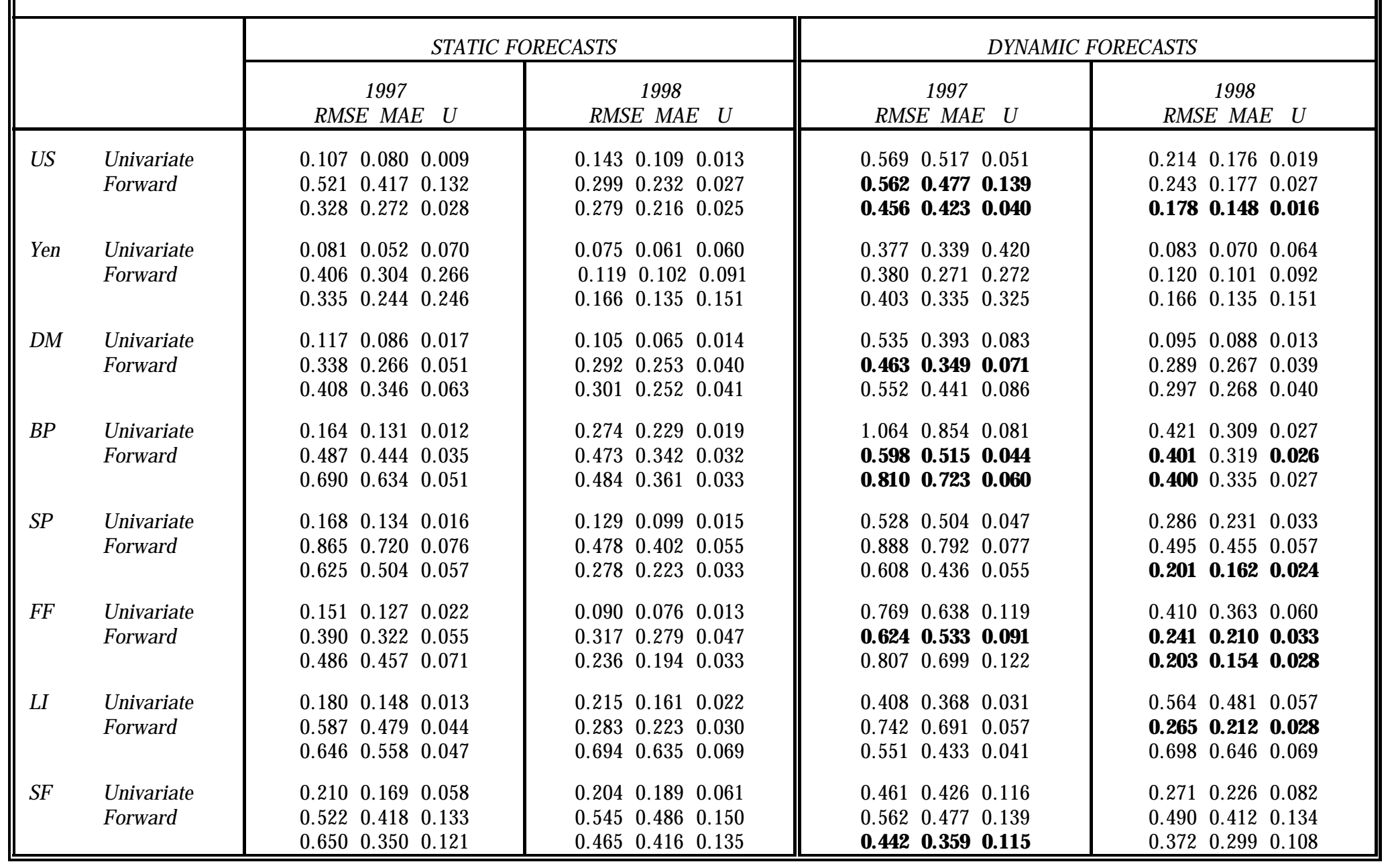

Note: $\quad$ Root M ean Square Error (RM SE), M ean A bsolute Error (M AE) and Theil's U statistics for static and dynamic forecasts obtained from AR (3) univariate autoregressions, as well as from a regression of the interest rate on the corresponding forward rate, appropriately lagged. Bold figures denote cases where the Forward model predicts better than the univariate model. 
But equation (9) is an ex-post regression that allows for a wide array of maturity comparisons without need of assumptions of the kind we made before when comparing 1- versus 3-month interest rates. We use it to compare 1-, 3-, 6- and 12-month returns against each other in each Eurocurrency.

$$
\begin{gathered}
r_{t}^{3} \cdot \frac{1}{3}\left(r_{t}^{1} \% E_{t} r_{t \%}^{1} \% E_{t} r_{t \%}^{1}\right) \\
r_{t}^{6} \cdot \frac{1}{2}\left(r_{t}^{3} \% E_{t} r_{t \%}^{3}\right) \\
r_{t}^{12} \cdot \frac{1}{2}\left(r_{t}^{6} \% E_{t} r_{t \%}^{6}\right)
\end{gathered}
$$

if we substitute realized interest rate values for expectations and use the same transformation as in (8), we have the following variants to (9):

$$
\begin{gathered}
\frac{r_{t \% 2}^{1} \% r_{t \% 2}^{1} \& 2 r_{t}^{1}}{3}, " \% \$\left(r_{t}^{3} \& r_{t}^{1}\right) \\
\frac{r_{t \%}^{3} \& r_{t}^{3}}{2}, " \% \$\left(r_{t}^{6} \& r_{t}^{3}\right) \\
\frac{r_{t \%}^{6} \& r_{t}^{6}}{2}, " \% \$\left(r_{t}^{12} \& r_{t}^{6}\right)
\end{gathered}
$$

A forecasting exercise was performed on the regressions in Section 3, which allow for using a current long/short-term spread to predict future short-term rates. For instance, for the 3- versus 6-month comparison, we have: $r_{t}^{6} \& r_{t}^{3}, \frac{1}{2} E_{t}\left(r_{t \%}^{3} \& r_{t}^{3}\right) \% d_{t}$, which suggests estimating: $\frac{1}{2}\left(r_{t \%}^{3} \& r_{t}^{3}\right), \quad " \% \$\left(r_{t}^{6} \& r_{t}^{3}\right) \% v_{t \%}$ from which forecasts of $r_{t \%}^{3}$ can be easily obtained. Similarly, we can produce forecasts for $r_{\mathrm{t} \%}^{6}$ from: $\frac{1}{2}\left(r_{\mathrm{t} \%}^{6} \& r_{t}^{6}\right), \quad " \% \$\left(r_{t}^{12} \& r_{t}^{6}\right) \% v_{t \%}$

This is a sensible way to produce forecasts out of our previous models. They incorporate the structure from the Expectations Hypothesis, but not all of its restrictions. A more restricted alternative would be to use the previous regressions, but imposing the hypothesis: $H_{0}: "=0, \$=1$, specially if it has not been rejected by the data. This should be considered as a baseline forecast, to be beaten by other proposed alternatives, leading to the forecasting equalities:

$$
\begin{gathered}
r_{t}^{1}{ }^{1} 3\left(r_{t \& 2}^{3} \& r_{t \& 2}^{1}\right) \& r_{t \& 1}^{1} \% 2 r_{t \& 2}^{1} \\
r_{t}^{3}, 2\left(r_{t \& 3}^{6} \& r_{t \& 3}^{3}\right) \% r_{t \& 3}^{3} \\
r_{t}^{6} \quad 2\left(r_{t \& 6}^{12} \& r_{t \& 6}^{6}\right) \& r_{t \& 6}^{6}
\end{gathered}
$$


A third alternative consists on solving each equation for the most advanced interest rate. For instance, from the first regression, we get:

$$
r_{t}^{1} \quad 3 " \% \$\left(r_{t \& 2}^{3} \& r_{t \& 2}^{1}\right) \& r_{t \& 1}^{1} \% 2 r_{t \& 2}^{1}
$$

and similarly, from the others:

$$
\begin{aligned}
& r_{t}^{3}, 2 " \% 2 \$\left(r_{t \& 3}^{6} \& r_{t \& 3}^{3}\right) \& r_{t \& 3}^{3} \\
& r_{t}^{6}, 2 " \% \frac{1}{2} \$\left(r_{t \& 6}^{12} \& r_{t \& 6}^{6}\right) \% r_{t \& 6}^{6}
\end{aligned}
$$

which suggest estimating:

$$
\begin{gathered}
r_{t}^{1} r_{1}{ }^{1} \$_{1}\left(r_{t \& 2}^{3} \& r_{t \& 2}^{1}\right) \% \$_{2} r_{t \& 1}^{1} \% \$_{3} r_{t \& 2}^{1} \\
r_{t}^{3}{ }_{1}{ }_{1} \% \$_{1}\left(r_{t \& 3}^{6} \& r_{t \& 3}^{3}\right) \% \$_{2} r_{t \& 3}^{3} \\
r_{t}^{6},{ }_{1} \% \$_{1}\left(r_{t \& 6}^{12} \& r_{t \& 6}^{6}\right) \% \$_{2} r_{t \& 6}^{6}
\end{gathered}
$$

This last set of regressions is again compatible with the $\mathrm{EH}$, but it does not impose several of its restrictions. In particular, the restrictions that led to (8) are not incorporated in them. If the EH strictly holds, not including its restrictions would lead to inefficient estimates and, most likely, some forecasting deterioration. On the other hand, if the EH does not hold, we might be better off by not including all of its restrictions in the forecasting model.

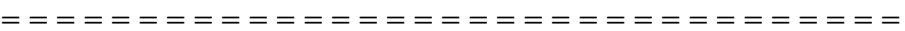

We have two benchmark for forecast comparison: on the one hand, univariate ARIM A models use just the past of the shorter-term interest rate being forecast, without any reference to the term structure. On the other extreme, we have models (10), which are heavily restricted, according to the $\mathrm{EH}$ of the formation of the term structure. In (10), there is no free parameter to be estimated. In between these two, we have the set of regressions (9) which project an average of short-term rates on a current spread, leading to the forecasting formulas (11), and regressions (11), which leave all coefficients unconstrained.

Our results clearly show that, even though they may occasionally produce a good fit, regression models that incorporate in some degree constraints imposed by the $\mathrm{EH}$ of the term structure do not produce better forecasts than univariate autoregressions, unrelated to the $\mathrm{EH}$ or almost any other theory of the formation of the term structure. Only under the segmentation hypothesis, which sees returns at different maturities as essentially uncorrelated, would a univariate model make efficient use of the available information. 
Prof. Mark P. Taylor

Editor

A pplied Financial Economics

Department of Economics

Oxford U niversity

$M$ anor Road, Oxford

OX1 3UL, UK

Somosaguas, april 28, 1999

Dear Professor Taylor:

Please, find enclosed three copies of our paper: $C$ an forward rates be used to improve interest rate forecasts?, which we would like to be considered for publication in A pplied Financial Economics.

Thanks for your attention. Sincerely,

\author{
A Ifonso N ovales \\ D epartamento de Economía Cuantitativa \\ Universidad Complutense \\ Somosaguas \\ 28223 M adrid \\ Spain
}


Prof. Mark P. Taylor

Editor

A pplied Financial Economics

Department of Economics

Oxford U niversity

$M$ anor Road, Oxford

OX1 UUL, UK

Somosaguas, october 28, 1999

Dear Professor Taylor:

I would appreciate if you could corroborate for me that my paper: Can forward rates be used to improve interest rate forecasts?, written jointly with $\mathrm{E}$. Dominguez, is being evaluated for possible publication in A pplied Financial Economics.

Thanks for your attention. Sincerely,

\author{
A Ifonso N ovales \\ D epartamento de Economía Cuantitativa \\ U niversidad Complutense \\ Somosaguas \\ 28223 M adrid \\ Spain
}


Professor M ark P. Taylor

Warwick Business School

The U niversity of W arwick

W arwickshire

CV 4 7AL

UK

Somosaguas, June 12, 2000

Dear Professor Taylor:

I would appreciate if you could give me some information regardinbg the current status of my paper: Can forward rates be used to improve interest rate forecasts?, written jointly with $\mathrm{E}$. Dominguez, which was sent for evaluation to A pplied Financial Economics on A pril 28, 1999.

In previous correspondence, you told me that the paper was assigned the code number: $99131 / \mathrm{AF} / 99$.

Thanks a lot in advance for your attention.

Sincerely,

\author{
A Ifonso Novales \\ D epartamento de E conomía Cuantitativa \\ U niversidad Complutense \\ Somosaguas \\ $28223 \mathrm{M}$ adrid \\ Spain
}

